\title{
Assessment and Analysis of a Grid-Tied Photovoltaic System with Net-Metering for State University in Pampanga
}

\author{
Edgardo M. Santos
}

\begin{abstract}
The utilization of renewable and eco-friendly source of energy which is also referred as "Alternative Energy" is now being recognized around the world, particularly the Solar Energy. The study proposes a grid-tied photovoltaic system with net-metering that generates electricity that is linked in the electrical grid, where in excess power is sold to the utility company. The objective is to improve the cost of energy consumption of Don Honorio Ventura State University Main Campus by designing and assessing Electrical Power System that lessens the dependency on the Distribution Utility (DU). The design of the system used with respect to the roofing area per building is $(3,464) 300$ Watts polycrystalline PV panels, (2) uni-directional or (1) bi-directional meter for monitoring the import and export energy, and $30 \mathrm{~kW}-100 \mathrm{~kW}$ inverter to convert DC (direct current) to AC (alternating current).The computation of the savings was based on the total $\mathrm{kWh}$ used per month with the system installed and includes the excess or export energy that is generated from the PV solar panels. Through the assessment of the proposed system, it will surely help Don Honorio Ventura State University (DHVSU) Main Campus to save monthly electric bill and lessen the dependency of the University to the utility grid. Since DHVSU's building are secondary metered by the Distribution Utility, there is a need to install separate PV System set-up tp meet the individual electrical requirement. The PV system will be installed via On-Grid Connection to the DU subject to the Net Metering rules and guidelines as stated by the Renewable Energy Act of 2008.
\end{abstract}

Keywords: Net Metering, Inverter, PV Solar Panel.

\section{INTRODUCTION}

One of the major problems of the world is the global warming, which destroys our environment. We are contributing on the carbon footprint coming from the power plant which harms our environment. Many researchers and developers are coming up with the use of not only an eco-friendly but also an environmental-friendly way of harnessing energy which is the renewable energies such as the Solar Energy, Hydroelectric Power, Biomass, Geothermal Energy and Wind Energy.

Renewable Energy is also referred as "Alternative Energy". It is an energy generated naturally of our nature. This kind of

Revised Manuscript Received on December 30, 2019.

* Correspondence Author

Edgardo M. Santos, Department of Electrical Engineering, Don Honorio Ventura State University, Bacolor, Pampanga, Philippines.

E-mail: edgardomsantos@yahoo.com

(C) The Authors. Published by Blue Eyes Intelligence Engineering and Sciences Publication (BEIESP). This is an open access article under the CC BY-NC-ND license (http://creativecommons.org/licenses/by-nc-nd/4.0/) energy is free and unlimited, unlike non-renewable energy which is limited and that might be exhaust in the near future. One of the most known and abundant free form of energy now a day is the solar energy. Solar energy is naturally produced by the sun. The light from the sun can be converted into electrical power by the use of the two major components which is the Solar Photovoltaic Panels and Inverters called as the Solar Photovoltaic System.

Electricity is a necessity in today's modern world. Before people can utilize electricity, it will pass a series of the process these are generation, transmission, and distribution. Electric distribution utilities do distribution of electricity. Each distribution utilities must ensure the power quality in their distribution system, and it must operate in safe, efficient, and with a high degree of reliability [1]. System reliability and efficiency are very vital in today's operation to all-electric utilities because of the fact that they can be ranked and can generate income for growth. One part of the system that contributes to its reliability and efficiency that taken into account is the transformer[2]. Solar Photovoltaic System converts the light from the sun from Direct Current (DC) to Alternating Current (AC) which is the standard electrical current use for powering most of the home appliances throughout the world. Investing in a PV System is a smart sensible choice that pays for itself overtime by harnessing the most abundant free form of energy available to us today. A grid-tied photovoltaic system is a system that generates electricity that is linked to the local power utility company's electrical grid, wherein the excess power generated by the photovoltaic panels can be sold to the utility company. If the photovoltaic panels can't reach the load requirement during cloudy and rainy days, the renewable energy generating local can rely on the electrical grid to supply the power demand.

Net-Metering or Bi-directional meter is responsible for monitoring the import and export or the exceeding energy of the system. Excess electricity is fed back into the utility's grid when the system is generating high amount of energy more than of what you need. When this happens, your bi-directional meter runs in reverse or what so called export energy. And when the system is producing lesser amount of energy, it will be drawn in the utility grid just as what it is before. This "back-and-forth" or "import-export" between the system and the grid ensures that the excess energy is not wasted and will still be used. With net-metering, the export energy is bought by the utility grid with lower rate per kilo-watt hour and it will be deducted from your monthly electric bill. 
According to Solar Power Industry in the Philippines (2013), there has been a general development in solar power generation in Asia opposed to Europe and the rest of the world, and ASEAN countries, including the Philippines, have a greater growth potential. Current electrical costs in the Philippines are the highest in Asia including Japan. This makes solar power more advantageous option in the Another Philippine milestone in the development of solar power using Photovoltaic system was in July 2013, when the net metering regulations and interconnection standards were released by the Philippine Energy Regulatory Commission and went into effect on July 25, 2013. This law now legalizes and thereby opens up the whole market of solar roof-top panels below $100 \mathrm{KW}$ in areas that on-grid in the Philippines. (Solar Power Industry in the Philippines, 2013) ${ }^{[1]}$

According to the Business Inquirer (2016) web site states that "In the Philippines, Robinsons Starmills unveil its first Solar Power Plant that supports the mall. This establishment demonstrates its commitment in protecting the environment from the adverse effects of carbon emissions; an institution like La Consolacion College has completed the installation of solar panels in its Manila campus, the first under a government program aimed at promoting renewable energy use in academic institutions as stated in Green Power (2015); other institutions had considered similar interest in renewable energy and these are :Manuel Luis Quezon University, St. Scholastica's College - Manila, St. Scholastica's Academy Marikina, University of Perpetual Help and Miriam College. Under the Department of Energy (DOE) initiated program, the solar power developer will sell the output of its facility to the school at rates lower than that charged by Manila Electric Cooperative (MERALCO).

The first phase of the project involves the installation of solar panels with a total capacity of 42.84 kilowatts $(\mathrm{kW})$. The second phase would produce an additional capacity of $90.27 \mathrm{~kW}$ once completed.

The net-metering facility allows La Consolacion to revert surplus electricity from the solar panels back to the grid, offsetting the equivalent amount to its power bill. La Consolacion tapped Trademaster Resources Corp to install the solar panels and net metering facility. The company will also maintain the solar panels.

According to Claire-Ann Marie C. Feliciano (2014), "The solar rooftop in La Consolacion is already operational. It involves two phases with total capacity reaching $133 \mathrm{~kW}$," he said in a phone interview. "The school and its partner, Trademaster Resources Corp., are currently processing documentation for the application under the net-metering," he added. The net-metering program allows customers that have their own renewable energy facility to sell to the grid any excess energy generated by its facility. Next to La Consolacion College, Mr. Marasigan said Manuel L. Quezon University-Manila will also have its own solar rooftop in cooperation with Propmech Corp. The government's solar rooftop program aims to install at least $100-\mathrm{kW}$ solar photovoltaic panels to power buildings of academic institution in Metro Manila. The private sector partner developers will sell the electricity generated by the facility at around P9.50 per kilowatt-hour (/kWh), which is cheaper by at least $\mathrm{P} 2 / \mathrm{kWh}$ because electricity rates in Metro Manila are pegged at about P11.50/kWh. Over the long term, the Energy department wants to implement the project in all private academic institutions -- including technical learning centers, research institutes, and academic centers. ${ }^{[2,3]}$

\section{ON GRID SYSTEM}

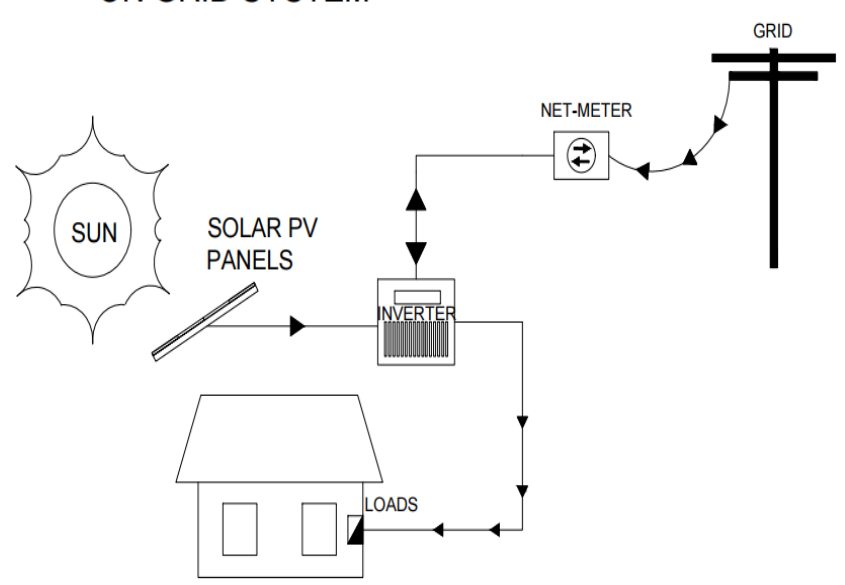

Figure 1.0 the flow of the study

Figure 1.0 shows the components of the study, when the light from the sun hits the modules of the solar photovoltaic (PV) panels, conversion of the solar energy into electricity takes place and produces direct current (DC) power. An inverter is used to invert the Direct Current (DC) power into an Alternating Current (AC) Power. The electrical current then flows from the inverter to the home electrical service panel that feeds the electricity into the households. During the day, if the solar system production exceeds the consumer electrical needs the excess electricity is fed back into the power grid. Net-meter is responsible for monitoring the import and export energy. Most local governments have a system of credits set in place that require utility companies to buy this excess energy back for various renewable energy standards, portfolios and goals. In addition to reducing your electric bill, this credit can be sold to utilities, this generates revenue to payback your cost of investment for the PV System and eventually turn a profit. At night, or anytime a household is using more electricity than a solar installation is producing, the extra energy needed to power the house is pulled from the grid, as it normally would be.

\section{METHODOLOGY}

\section{A. Electrical System Designing}

The proponents collected detailed floor plan at the Office of the Physical Plant and Facilities (OPPF) of the University in order to consider the computation for the roof area of each building so that the proponents will be able to design the system easily. The design for PV was determined through manual counting of electrical loads. The total computed electrical loads of all buildings that are connected to each secondary meter will determine the number of solar panels and total wattage needed for the design of the study. Since the aim of the study is to minimize the dependency of the university to distribution utility in order to attain maximum savings, the proponents had given attention to the sizes of PV panels with respect to the roof area per building. 


\section{B. Computation of Savings}

Computation of savings in terms of peso was based on three cases. In Case 1, total load demand of buildings per meter is multiplied by demand factor of $85 \%$ and divided by cell efficiency of $85 \%$ of the PV panel in order to achieve the demand power of per meter. For case 2, load demand is multiplied by $85 \%$ demand factor at an efficiency of $15.3 \%$ of PV panel. And Case 3 used the total load demand of the buildings per meter. In every case, demand power was computed in every building per meter and was used to compute for the kWh used with the system and the savings in terms of peso.

\section{RESULTS \& DISCUSION}

Computation of savings in terms of peso was based on three cases. Proponents had also considered different ways in analyzing and solving the savings of the university with the proposed study. In computing for the total kWh used when the system is installed, the proponents identified the period of consumption per building in terms of days. Obviously, offices like General Office under meter 1, used the basis of 20 working business days with 10 days as non-working days. Meter 2 is utilized for 24 days in a month with 6 days which has no classes.

Sunlight varies its intensity at any particular time of the day because of this the proponents had considered the average time in order to attain the most sunlight. Sun peak-hour of the local of the study was used. It is the hour during which the intensity of sunlight is 1,000 watts per square meter, by which PV panel can generate large amount of energy. The average sun peak hours at DHVSU is 5.5 hours, using manual system sizing tool of the Solar Systems Philippines Inc. Practically, PV Panels does not harnessed energy $100 \%$. For this reason, an $80 \%$ multiplier was used by the researchers, considering conversion of DC to AC is $80 \%$.

In Case 1, total load demand of buildings per meter is multiplied by demand factor of $85 \%$ and divided by solar efficiency of $85 \%$ in order to achieve the demand power of per meter. For case 2, load demand is multiplied by $85 \%$ demand factor at an efficiency of $15.3 \%$ of PV panel. According to Solaric Philippines, pure load demand is considered in computing the kWh at savings.

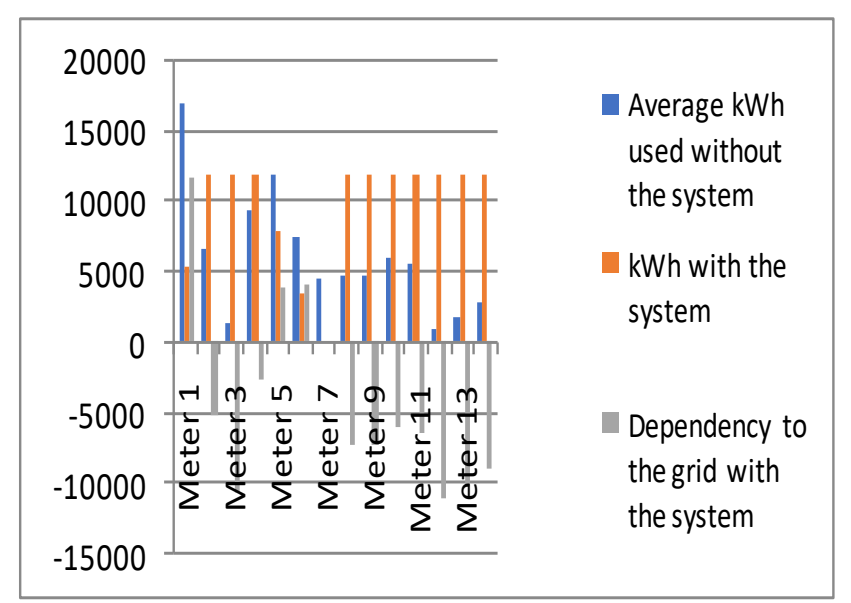

Figure 2.0 Case 1: Average kWh Used without the System, kWh Used with the System and the Dependency to the Grid with the System

The average $\mathrm{kWh}$ used without the system is based on the previous monthly electric bill of the University. In Figure 2.0, the total load demand per meter were multiplied by a demand factor of $85 \%$ and divided by efficiency of $85 \%$ in order to obtain the demand power per meter. Cell efficiency is the inverse of module efficiency of the solar panel. The dependency to the grid with the system was obtained by finding the difference between the average $\mathrm{kWh}$ used without the system and $\mathrm{kWh}$ used with the system. This serves as the dependency of the University to DU once net-metering is applied. Negative graph can be observed for the dependency to the grid with the system of other meters because the consumer needs not to depend to DU since it can generate energy sufficient to supply itself through the PV panels.

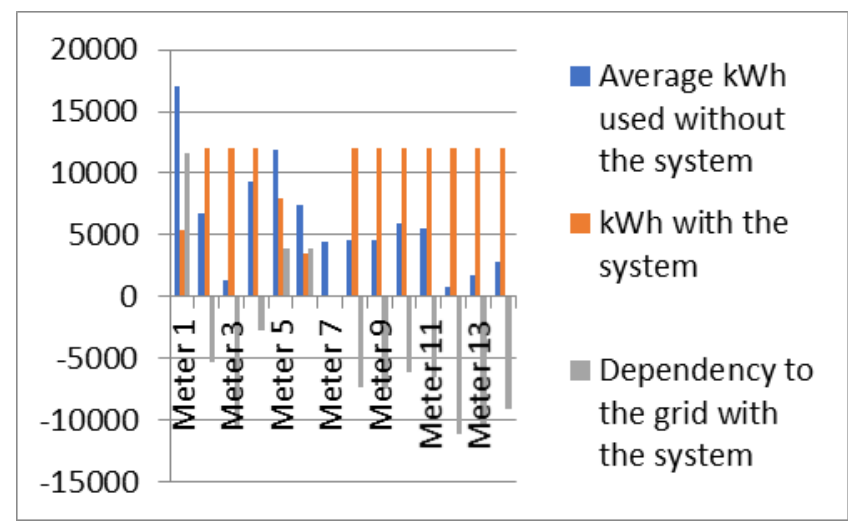

Figure 2.1 Case 2: Average kWh Used without the System, kWh Used with the System and the Dependency to the Grid with the System

In Figure 2.1, the load demand was used and was multiplied by $85 \%$ demand factor and divided with the module efficiency of $15.3 \%$ of the PV panel used. Graph for case 2 is similar with case 1 since both have the same energy used from PV panels for computation.

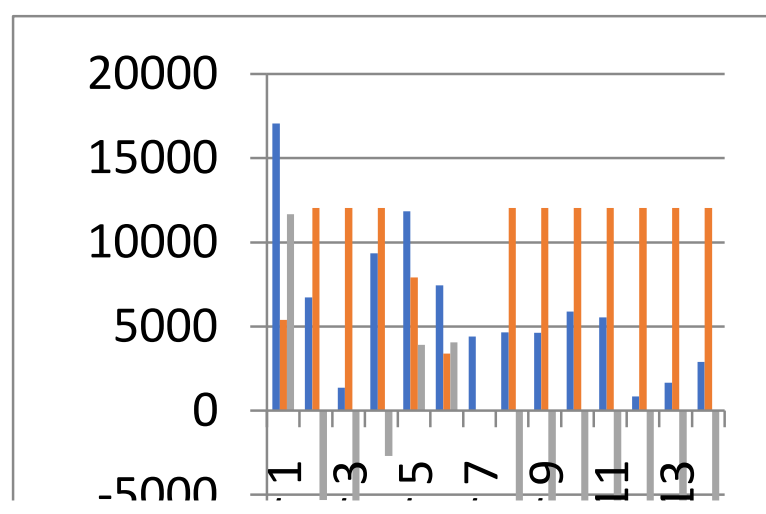

Figure 2.2 Case 3: Average kWh Used without the System, kWh Used with the System and the Dependency to the Grid with the System

In Figure 2.2, Based on the interview conducted with Solaric Philippines, purely load demand $\mathrm{kWh}$ and savings are just considered in computing. For this reason, kWh computed for case 1 and case 3 are the same since the load demand are common. 


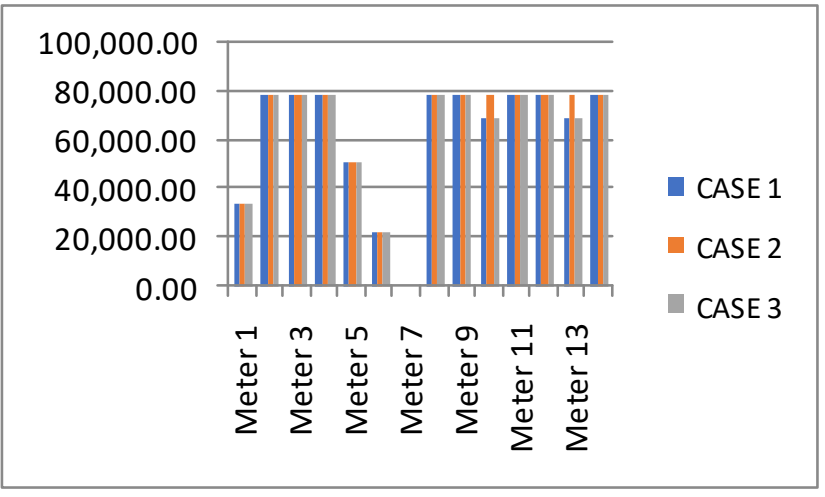

Figure 3.0 Computed Total Savings per Month with the System

Figure 3.0 shows the total savings of cases 1, 2, and 3 which are almost the same since: load demand of buildings is common, demand power is high, and installed PV panels are few producing less energy. Savings computation include the use of total wattage of PV panels on Meters 1, 2, 3, 4, 5, 8, 9, 11 , at 14 . On the other hand, Meters 6, 10, 12 at 13 were the basis for demand power of loads of all buildings since PV panels used here have greater capacity. Excess energy is generated by the panels which are exported through the net metering system.

The return of investment will be after 4 years and 5 months for Cases 1 and 3, and 4 years and 3 months for Case 2 if the proposed system design will be adopted to the University.

\section{CONCLUSION}

Based on the study conducted several conclusions were formulated. First, carbon footprint will be lessening. Second, with the proposed system, the dependency of DHVSU Main Campus to the distribution utility was minimized. Third, analysis process has facilitated in the identification and estimation of total quantities of solar panels, inverters, and load demand of the system. Lastly, the study is purely feasible as based on the output from three presented cases.

\section{RECOMMEDATIONS}

For future development of the study, it is recommended to design one main meter inside DHVSU Main Campus wherein the total consumption in terms of kWh used every day and the total energy that is exported in the utility grid will be monitored properly. This will make it easier to identify the savings of the university by monitoring the import and export energy of the university. Due to high numbers of inverters that were used per meter, it is also recommended to design an inverter bank that is interconnected to all the buildings and establishments in the University.

\section{REFERENCES} Solar Power in the Philippines,
http://helioscsp.com/solar-power-industry-in-the-philippines/ Business Inquirer http://business.inquirer.net/210675/210675\#ixzz55jhLdoic

3. Claire-Ann Marie C. Feliciano 2014, La Consolacion Collegehttp://www.bworldonline.com/content.php?section=Corporate \&title=la-consolacion-college-solar-rooftop-starts-operations\&id=940 62

4. Solar Powered Motion Activated Electrical System of St. Martin De Porres and Daycare Center of Barangay Mount Diaz, Porac,
Pampanga, Leoncio S. Caling Jr., Rolly A. Cordova, Venjie S. Culala, and Jeferson C. Uson, Don Honorio Ventura State University 2013

5. A STUDY ON THE EFFECTS OF SOLAR POWER, Jonathan Keith Hayes, University of Arkansas, Department of Electrical Engineering, Spring 2012

\section{AUTHOR PROFILE}

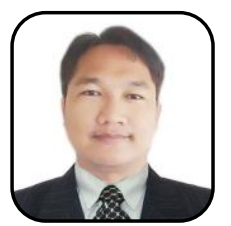

Edgardo M. Santos Chairperson, Electrical Engineering Department of Don Honorio Ventura State University (DHVSU). A Licensed Electrical Engineer, Master Electrical, Master Plumber, Professional Teacher and rank number 7 for the September 2007 Registered Master Electrician Board Examinations. A Graduate of Doctor of Philosophy in Engineering Management (PhD. EnM) at Nueva Ecija University of Science and Technology (NEUST). A senior member of Institute on Integrated Electrical Engineers. Electrical System Design, High Rise Building Designs and renewable energies are his field of research. 